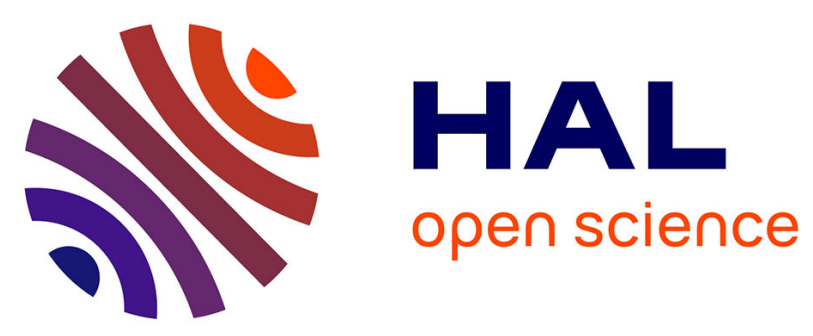

\title{
MAGNETIC PROPERTIES OF (001)Fe/(001)Cr bcc MULTILAYERS
}

F. Nguyen van Dau, A. Fert, P. Etienne, M. Baibich, Jean-Marc Broto, J. Chazelas, G. Creuzet, A. Friederich, S. Hadjoudj, H. Hurdequint, et al.

\section{- To cite this version:}

F. Nguyen van Dau, A. Fert, P. Etienne, M. Baibich, Jean-Marc Broto, et al.. MAGNETIC PROPERTIES OF (001)Fe/(001)Cr bcc MULTILAYERS. Journal de Physique Colloques, 1988, 49 (C8), pp.C8-1633-C8-1634. 10.1051/jphyscol:19888746 . jpa-00228988

\section{HAL Id: jpa-00228988 https://hal.science/jpa-00228988}

Submitted on 1 Jan 1988

HAL is a multi-disciplinary open access archive for the deposit and dissemination of scientific research documents, whether they are published or not. The documents may come from teaching and research institutions in France or abroad, or from public or private research centers.
L'archive ouverte pluridisciplinaire HAL, est destinée au dépôt et à la diffusion de documents scientifiques de niveau recherche, publiés ou non, émanant des établissements d'enseignement et de recherche français ou étrangers, des laboratoires publics ou privés. 


\title{
MAGNETIC PROPERTIES OF (001)Fe/(001)Cr bcc MULTILAYERS
}

\author{
F. Nguyen van Dau $\left({ }^{1}\right)$, A. Fert $\left({ }^{1}\right)$, P. Etienne $\left({ }^{2}\right)$, M. N. Baibich $\left({ }^{1}\right)$, J. M. Broto $\left({ }^{1}\right)$, J. Chazelas $\left({ }^{2}\right)$, \\ G. Creuzet $\left({ }^{2}\right)$, A. Friederich $\left({ }^{2}\right)$, S. Hadjoudj $\left({ }^{1}\right)$, H. Hurdequint $\left({ }^{1}\right)$, J. P. Redoulès $\left({ }^{3}\right)$ \\ and J. Massies ( ${ }^{4}$ ) \\ (1) Laboratoire de Physique des Solides, Université Paris-Sud, 91405 Orsay, France \\ ( ${ }^{2}$ ) Laboratoire Central de Recherche, Thomson CSF, F-91405 Orsay, France \\ ( $\left.{ }^{3}\right)$ Laboratoire de Physique des Solides, Sophia Antipolis, F-06560 Valbonne, France \\ (4) Laboratoire de Physique des Solides, INSA, F-31077 Toulouse, France
}

Abstract. - We present magnetization, torque and magnetoresistance measurements on (001) Fe/(001)Cr multilayers prepared by MBE. Our main results are: a) evidence of antiferromagnetic interlayer couplings, b) the observation of a huge magnetoresistance.

We have prepared (001) Fe/(001)Cr bcc superlattices by MBE on (001)GaAs substrates. The epitaxial relationships are determined by in situ RHEED and checked by $\mathrm{X}$ ray diffraction [1]. Auger sputter depth profiling and Scanning Transmission Electron Microscopy (Fig. 1) indicate that there is no significant intermixing at the interfaces [1]. The layer thicknesses range from $9 \AA$ to $90 \AA$. We have performed magnetization (vibrating sample system), torque and magnetoresistance measurements on these multilayers.

We first present magnetization results on multilayers (ml) with a $\mathrm{Cr}$ thickness larger than $30 \AA$. At this thickness the interlayer coupling turns out to be negligible. As shown by figure 2, the easy axis is [100]. With $H$ along the [110] hard axis $M$ reaches its saturation value $M_{\mathrm{s}}$ at about $1 \mathrm{kG}$. The remanent magnetization along $[110]$ is approximately $M_{s} / \sqrt{2}$, which is consistent with $M$ at $\pi / 4$ along [100] or [010]. $M_{\mathrm{s}}$ is generally in a range of $\pm 15 \%$ around $M_{s}$ of bulk iron (it is hard to establish whether the scatter of the values of $M_{\mathrm{s}}$ arises from the uncertainty on the geometry of the samples or from some $\mathrm{Cr}$ contribution). By analysing the angular and field dependences

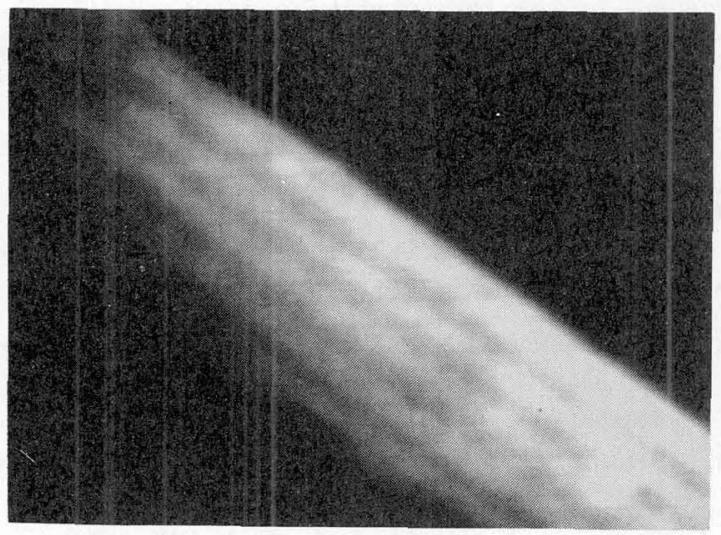

Fig. 1. - Cross section of a Fe60 $\AA$ / Cr60 $\AA$ ml obtained by Scanning Transmission Electron Microscopy.

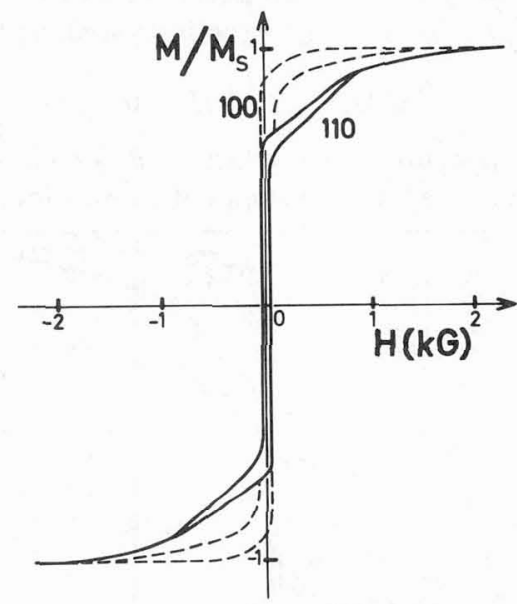

Fig. 2. - Hysteresis loop of a $(\text { Fe60 } \AA / \operatorname{Cr} 60 \AA)_{5}$ multilayer at $77 \mathrm{~K}$ for an applied field along the [100] and [110] directions in the multilayer plane 5 is the number of bilayers.

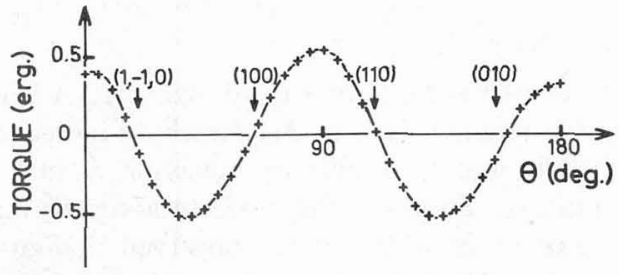

Fig. 3. - Torque versus field angle at $4.2 \mathrm{~K}$ for a (Fe60 $\AA / \mathrm{Cr} 60 \AA)_{5}$ multilayer. The field $(9 \mathrm{kG})$ rotates in the plane of the multilayer.

of torque curves with an applied field in the ml plane (Fig. 3), we derive the anisotropy constant $K_{1}, K_{1} \approx$ $52 \times 10^{4} \mathrm{erg} / \mathrm{cm}^{3}$ at $4.2 \mathrm{~K}$, for the $\mathrm{ml}$ of figures 2,3 (to be compared with $K_{1} \approx 57.8 \times 10^{4} \mathrm{erg} / \mathrm{cm}^{3}$ for bulk iron). We have also combined torque, Hall effect and ferromagnetic resonance to study the perpendicular anisotropy, as it will be reported elsewhere.

We proceed with results on $\mathrm{ml}$ with thin $\mathrm{Cr}$ layers. Figure 4 shows that for decreasing $\mathrm{Cr}$ thicknesses (below about $30 \AA$ ) the magnetization becomes harder 
to saturate (the tilt of the loop increases) and the remanent magnetization decreases to almost zero. This behavior can be accounted for by an antiferromagnetic (AF) exchange coupling between Fe layers through $\mathrm{Cr}$. Such AF coupling have already been put forward to explain light scattering [2] and SPLEED [3] experiments on $\mathrm{Fe} / \mathrm{Cr} / \mathrm{Fe}$ sandwiches. To interpret our results in the simplest way, we assume a fixed magnetic moment ( $=M_{\mathrm{s}} t_{\mathrm{Fe}}$ per surface unit if $t_{\mathrm{Fe}}$ is the thickness) and a coupling energy $J \cos \theta$ between two neighbour $\mathrm{Fe}$ layers $(\theta=$ angle between the magnetizations). With an applied field (see inset of Fig. 5), the total energy per layer and surface unit is written:

$$
E=-J \cos 2 \varphi-M_{s} t_{\mathrm{Fe}} H \sin \varphi
$$

By minimizing $E$ one derives $\sin \varphi$ and then the following expression of the magnetization along the field direction:

$$
M M_{\mathrm{s}}=M_{\mathrm{s}} t_{\mathrm{Fe}} H / 4 \mathrm{~J}
$$

We show in figure 5 the values of $J$ for $t_{\mathrm{Fe}}=30 \AA$ derived from the low field slopes of figure 4 (our results

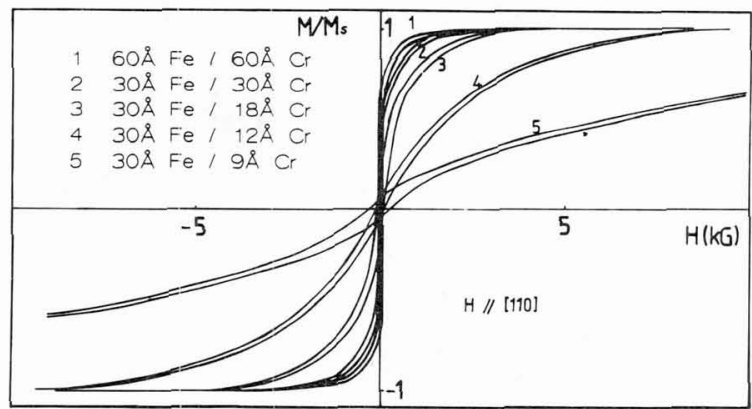

Fig. 4. - Hysteresis loops at $4.2 \mathrm{~K}$ with an applied field along [110] in the $\mathrm{ml}$ plane for several systems: 1) $\left.(\operatorname{Fe} 60 \AA / \operatorname{Cr} 60 \AA)_{5}, 2\right)(\operatorname{Fe} 30 \AA / \operatorname{Cr} 30 \AA)_{10}$, 3) $(\mathrm{Fe} 30 \AA / \mathrm{Cr} 18 \AA)_{30}$, 4) $\left.(\mathrm{Fe} 30 \AA / \mathrm{Cr} 12 \AA)_{10}, 5\right)$ $(\mathrm{Fe} 30 \AA / \mathrm{Cr} 9 \AA)_{40}$.

on multilayers with different $t_{\mathrm{Fe}}$ down to $12 \AA$ lead to not very different values of $J$ ). $J$ steeply increases as $t_{\mathrm{Gr}}$ decreases and an oscillatory behavior, as in $\mathrm{Y} / \mathrm{Gd}$ [4], is unlikely. Equation (2) predicts a strictly linear dependence in $H$ which is not observed in figure 4 . The observed dependence can be accounted for more closely by assuming that the moments within the layers are more tilted towards $H$ than the interface moments (and also by taking into account the anisotropy). The model leading to equation (2) is obviously too simple.

We finally summarize our magnetoresistance results. As shown in Figure 6, the variation of $R$ follows that of the magnetization and saturates at about the same filed. The magnetoresistance is very large: in figure 5 , $R$ is deduced by about a factor of 2 at high fields; more generally $\Delta R / R$ is large for thin Cr layers. This huge magnetoresistance appears to arise from changes of the electron transmission through of $\mathrm{Cr}$ when the moments of the $\mathrm{Fe}$ adjacent layers are brought to be parallel.

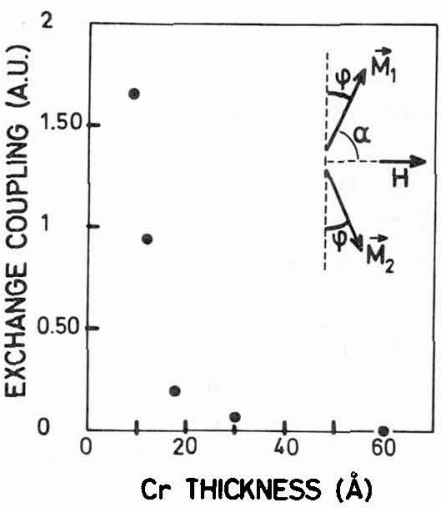

Fig. 5. - Interlayer coupling constant $J$ for $t_{\mathrm{Fe}}=30 \AA$ versus $\mathrm{Cr}$ thickness. Inset: scheme for the magnetic moments of two coupled layers in a magnetic field.

In conclusion, the main results of our measurements are: a) clear evidence of antiferromagnetic interlayer couplings, b) the observation of a huge magnetoresistance (factor of 2).

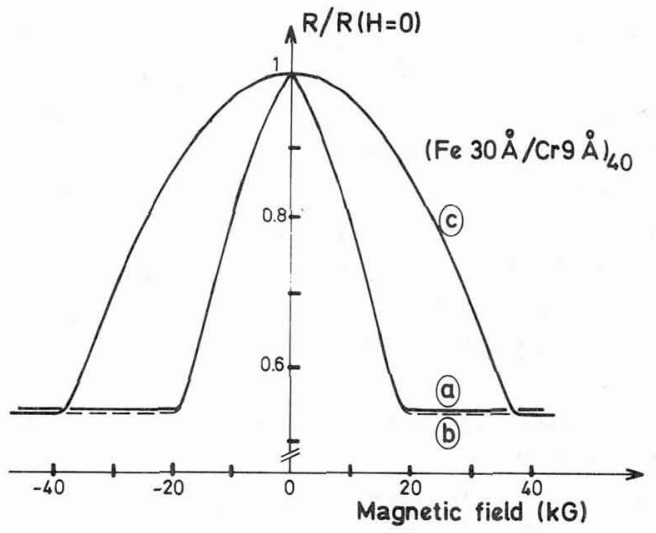

Fig. 6. - Magnetoresistance of a $\left(\mathrm{Fe}_{30 \AA} / \mathrm{Cr}_{90 \AA}\right)_{40}$ multilayer. The current is along [110] and the field in the $\mathrm{ml}$ plane along the current direction (curve a), or in the $\mathrm{ml}$ plane perpendicularly to the current (curbe b) or perpendicular to the $\mathrm{ml}$ plane (curve $\mathrm{c}$ ). There is a very small difference between the curves in increasing and decreasing field (hysteresis) that we have not represented on the figure. Yhe $\mathrm{ml}$ is covered by a $100 \AA \mathrm{Ag}$ protection layer. This means that the magnetoresistance of the $\mathrm{ml}$ alone is certainly still higher.

\section{Acknowledgments}

Work supported by MRES and DRET grants. We thank J. P. Renard for some SQUID measurements.

[1] Etienne, P., Creuzet, G., Friederich, A., Nguyen Van Dau, F., Fert, A., Massies, J., to appear in Appl. Phys. Lett.

[2] Grünberg, P., Schreiberg, R., Pang, Y., Brodsky, M. B., Phys. Rev. Lett. 57 (1986) 2442.

[3] Carbone, C. and Alvarado, S. F., Phys. Rev. B 36 (1987) 2433.

[4] Yafet, Y., J. Appl. Phys. 61 (1987) 4058. 